\title{
Sexual satisfaction among italian university students
}

\author{
Laura Terzera* ${ }^{*}$, Stefania Maria Lorenza Rimoldi and Elisa Barbiano di Belgiojoso
}

\author{
* Correspondence: laura.terzera@ \\ unimib.it \\ Università di Milano, Bicocca Via \\ Bicocca degli Arcimboldi, 8, 20126 \\ Milan, Italy
}

\begin{abstract}
This paper examines the determinants of sexual satisfaction among Italian young men and women at the beginning of their adulthood, taking into account the different stages of sentimental and sexual transitions. We based the analyses on the data collected in 2017 by the SELFY Survey on a sample of 7842 university students in Italy. Results of the logistic regression models highlight that, above all, sexual satisfaction is positively associated with the frequency of intercourse within a stable and exclusive relationship. Furthermore, results highlight the essential role of all transitions, sexual and sentimental, in enhancing sexual satisfaction, both in a positive and negative direction. Religion has a positive effect too, but only among students who have not yet had intercourse, expressing a protective effect of the adherence to beliefs. Significant differences between young men and women emerged mainly concerning performance, other conditions being equal.

Keywords: Sexual satisfaction, Young people, Italy
\end{abstract}

\section{Introduction}

During the past century, the topic of sexual satisfaction has attracted increasing interest, with its crucial role evidenced in studies on sexual health, well-being and quality of life (Rainer \& Smith, 2012; Sánchez-Fuentes, Santos-Iglesias, \& Sierra, 2014). The World Health Organization (WHO) has stated the importance of sexual satisfaction as a fundamental dimension of sexual health, defining it as a sexual right (WHO, 2006, 2010).

Two main approaches stand out in quantitative studies on this theme: the first aims to devise ad hoc indicators by investigating every single aspect of sexual life - for example, intention, desire, arousal and orgasm (Levine, 1992; Štulhofer, Buško, \& Brouillard, 2010; Young, Denny, Luquis, \& Young, 1998; Young, Denny, Young, \& Luquis, 2000); the second focuses on the study of interrelated factors. Both individual and relational characteristics, as well as factors such as religion, values or social support, affect sexual satisfaction and result in a puzzle of sexual satisfaction conditions (Sánchez-Fuentes et al., 2014).

Among structural characteristics, age plays a primary role. Various studies underline that, although sexual satisfaction decreases as age increases, the effect of physical and

(c) The Author(s). 2020 Open Access This article is licensed under a Creative Commons Attribution 4.0 International License, which permits use, sharing, adaptation, distribution and reproduction in any medium or format, as long as you give appropriate credit to the original author(s) and the source, provide a link to the Creative Commons licence, and indicate if changes were made. The images or other third party material in this article are included in the article's Creative Commons licence, unless indicated otherwise in a credit line to the material. If material is not included in the article's Creative Commons licence and your intended use is not permitted by statutory regulation or exceeds the permitted use, you will need to obtain permission directly from the copyright holder. To view a copy of this licence, visit http://creativecommons.org/licenses/by/4.0/. 
relational factors, as well as intimacy, changes with age (Lindau \& Gavrilova, 2010; Moyano \& Sierra, 2013; Sánchez-Fuentes et al., 2014). The literature highlights that some factors consistently influence the sexual satisfaction of adults but may not have the same influence on people's sexual satisfaction at the beginning of their sexual life; on the other hand, some other factors influence the sexual satisfaction of young people more intensely than that of older people (Higgins, Mullinax, Trussell, Davidson, \& Moore, 2011). For example, health problems more often affect adults, while body image is a crucial factor for sexual satisfaction among younger people (Auslander et al., 2007). Moreover, research recognizes the importance of young adults' sexual satisfaction for its implications in relationships, marriages and family formation (Auslander et al., 2007; Higgins et al., 2011; Pedersen \& Blekesaune, 2003; Sprecher, 2002), and studies are increasingly devoted to this subgroup of population.

Focusing on this subgroup, and using data from the SELFY Survey (Dalla Zuanna, Caltabiano, Minello, \& Vignoli, 2019) conducted in 2017 among students attending major Italian universities, this paper aims to cover the literature's lack of research on sexual satisfaction of Italian youths. As with most scholars, we recognize the multidimensional nature of this subject, and we examine the effect of various factors on the sexual satisfaction of Italian university students by using two perspectives: gender and the kinds of sentimental and sexual experiences.

The rest of the paper is organized as follows: in the next section, we describe the theoretical framework on which we grounded our research strategy and research hypotheses; section three contains the description of data, measures and methods of analysis; and results and conclusions are reported in sections four and five, respectively.

\section{Theoretical framework and research hypotheses}

Scholars almost universally define sexual satisfaction (hereinafter SS) as 'an affective response arising from one's subjective evaluation of the positive and negative dimensions associated with one's sexual relationship' (Lawrance \& Byers, 1995, p. 268). By adopting the scheme proposed by Sánchez-Fuentes et al. (2014) in their systematic review of the scientific literature on SS, determinants can be classified into four groups, ordered in an ascending scale from micro to macro levels. The first group, including individual variables such as socio-demographic and psychological characteristics as well as physical and psychological health status, constitutes the micro level. The second group, including variables associated with intimate relationships and sexual response/behaviour (e.g., marital satisfaction, communication, sexual assertiveness, sexual functioning, sexual dysfunction), constitutes the meso level. The third group, identified by SánchezFuentes et al. (2014) as factors related to social support and family relationships, constitutes the exo level. Finally, the fourth group, relating to cultural beliefs and values, such as religiosity, constitutes the macro level.

The literature shows how some of these factors assume a different degree of importance among young people (Lindau \& Gavrilova, 2010; Sánchez-Fuentes et al., 2014). Concerning the micro-level factors, many studies reveal that, among the sociodemographic factors associated with sexual satisfaction, high self-esteem and a positive body image predict greater sexual satisfaction (Bajos, Wellings, Laborde, \& Moreau, 2010; Calogero \& Thompson, 2009; Pujols, Meston, \& Seal, 2010). Moreover, selfesteem and body image are particularly associated among youths (Agam, Tamir, \& 
Golan, 2015), playing a specific role especially among girls (Auslander et al., 2007; Higgins et al., 2011; Milhausen, Buchholz, Opperman, \& Benson, 2015), for whom the negative effect of body image disaffection and lower self-esteem on SS is more prevalent (Clay, Vignoles, \& Dittmar, 2005; Furnham, Badmin, \& Sneade, 2002). Gender seems to play an ambiguous role among young people: some studies reveal that women report a lower sexual satisfaction than men (Oliver \& Hyde, 1993; Ziherl \& Masten, 2010), while others find few or no gender differences, with the predictors under study being more notable for their gender similarities than for their gender differences (Higgins et al., 2011; Petersen \& Hyde, 2010). This ambiguity could follow the masculine-feminine dichotomisation of the social construction of sexuality: in masculine culture, sexuality has been understood as performance and outcome, while feminine culture has emphasized sensitivity and relationship-related characteristics (Hofstede, 1998). It follows a sexual double standard supporting gender-appropriate sexual behaviours (Crawford \& Popp, 2003) that has important implications for sexual development. To varying degrees according to the country and the period in history under consideration, the general belief is that casual sex and multiple sexual partners (Milhausen \& Herold, 1999), as well as the expression of sexual desire (Crawford \& Popp, 2003), are more acceptable for men than for women. Therefore, gender differences in influencing factors could be due to adherence to these cultural patterns, especially at the beginning of sexual life when the definition of one's gender sexuality is underway (Pedersen \& Blekesaune, 2003; Petersen \& Hyde, 2010).

Sexual biography, orientation and attitudes are further crucial aspects of the micro dimension. Regarding sexual biography, the first sexual intercourse is a symbolic touchstone of young people's development (Carpenter, 2005), representing a rite of passage into sexual adulthood and meaningful connections to future sexual experiences and sexual health. Consequently, the characteristics of this passage and its mental representation are factors specifically influencing the sexual satisfaction of young people (Higgins et al., 2011). The age at which people first engage in sexual intercourse is a useful control variable when studying SS among young people (Pedersen \& Blekesaune, 2003), as is the time that has elapsed between that first intercourse and subsequent sexual encounters. Higgins et al. (2011) showed that SS increases between someone's first intercourse and their current sex life, especially among women. Concerning sexual orientation, consensus among scholars is lacking. In some studies, homosexuality was associated with increased sexual satisfaction (Henderson, Lehavot, \& Simoni, 2009), whereas in others, no significant differences were found (McClelland, 2011). Among sexual attitudes, masturbation and the use of pornography are the most studied. Guilt feelings over masturbation still appear to play a significant role in the sexual lives of individuals, and in general, masturbation is considered less acceptable overall when practised while in an intimate relationship, causing a decrease in relational satisfaction (Levin, 2007; Miller, McBain, Li, \& Raggatt, 2019). Finally, Carroll et al. (2008) demonstrated increased acceptance among the younger generations regarding the use of Internet pornography, with it becoming a common behaviour. However, the effects of using sexually explicit material (pornography) on sexual satisfaction are either small (Štulhofer et al., 2010) or associated with lower sexual satisfaction (Maddox, Rhoades, \& Markman, 2011). 
Concerning the second-level (meso-level) factors associated with intimate relationships and sexual response, many quantitative studies on sexual satisfaction have highlighted the potent effects of the relational aspects. A satisfactory relationship generally enhances sexual satisfaction regardless of age (Hurlbert, Apt, \& Rabehl, 1993; Sánchez-Fuentes et al., 2014). Satisfaction relates to the kind of relationship and its length. Among adults, having a partner, cohabiting or being married (Lau, Kim, \& Tsui, 2005) are associated with higher sexual satisfaction (Sánchez-Fuentes et al., 2014), and there is a similar association among young people: 'unattached, sexually active young people were least satisfied with their sex lives than were marrieds, cohabitants and committed daters' (Pedersen \& Blekesaune, 2003, p. 192). The duration of the relationship matters, too, although there is no consensus regarding its effect on SS (Schmiedeberg \& Schröder, 2016). Some studies did not find any significant effects from the duration of the relationship (Carpenter, Nathanson, \& Kim, 2009; Ho, Cheung, \& Cheung, 2008; Pedersen \& Blekesaune, 2003), while other studies have shown differences between men and women (Heiman et al., 2011; Rehman, Rellini, \& Fallis, 2011). Moreover, there is evidence of an association between the duration of a relationship and a growing sense of boredom and routine in sexual life, even in studies relating to young people (Pedersen \& Blekesaune, 2003). As for young adults, the length of the relationship is a less relevant determinant for SS than having a satisfactory, stable, exclusive sentimental relationship (Auslander et al., 2007; Higgins et al., 2011; Sprecher, 2002). Indeed, exclusivity within a relationship raises interest among young people (Dalla Zuanna et al., 2019; Mercer et al., 2013).

Current sexual behaviour within a relationship is also included by scholars as a mesolevel factor influencing the SS of young people. Among these aspects, the frequency of sex and the variety of sexual behaviours are unanimously associated with increased sexual satisfaction (Haavio-Mannila \& Kontula, 1997; Hurlbert et al., 1993; Pedersen \& Blekesaune, 2003; Sánchez-Fuentes et al., 2014).

Regarding the exo-level factors, the characteristics of the family of origin, the relationship with parents and parent-provided sex education are the most analysed variables. These aspects have a generally positive, but limited, influence on SS. Social support and good relations with family predict greater sexual satisfaction (Ji \& Norling, 2004). However, sex education from parents affects girls and boys differently (Higgins et al., 2011), and no associations between sexual satisfaction and parental socio-economic conditions have been found (Pedersen \& Blekesaune, 2003).

One of the major representative variables of the macro-level factors is religion, which plays a different role in the SS of adults compared to that of young people. Davidson, Darling, and Norton (1995) showed that religious practice does not affect SS, while religiosity seems to have a negative impact on young adults' SS only when it is a strong belief and is associated with guilt and limited sexual knowledge (Higgins, Trussell, Moore, \& Davidson, 2010; Regnerus, 2007).

This quick excursus on the literature concerning the determinants associated with young people's SS reveals that having an ongoing relationship and having completed the transition to intercourse both emerge as positively associated to SS, without ambiguity in the results. However, if the picture is clear for those students in a sexually active couple, more ambiguity exists for those who do not have sexual experiences or do not have a stable partner. Different stages of sexual experiences (masturbation, petting, 
intercourse) along with relational conditions are key elements for sexual satisfaction of youths. To the best of our knowledge, these stages have been understudied in previous research.

Based on the possible interrelations between the variables involved at different stages, we compare homogeneous groups of students with respect to their stage of sentimental and sexual transition to adulthood. In this paper, 'transition' refers to having experienced an event at least once: more specifically, a sentimental transition occurs when at least one relationship is present in a student's biography; similarly, considering the sexual sphere, we consider 'sexual transition' as the experience of a particular sexual activity (masturbation, petting, intercourse) expressed in an individual's biography. Taking into account these different stages of transitions, we aim to fill the gap in the literature as regards the determinants of the sexual satisfaction of Italian youths and to contribute to the international debate on the ambiguous effects of some covariates. For these purposes, we formulate the following research hypotheses:

H1 - We expect that every typology of sexual transition (masturbation, petting, intercourse) positively affects the SS of Italian university students, as does the sentimental transition, but this lasts only among those students with a current partner. $\mathrm{H} 2$ - Despite the convergent behaviours of young men and women, we hypothesise that the masculine-feminine dichotomisation of the social construction of sexuality still conditions the determinants of Italian female and male satisfaction at the beginning of adulthood. Consequently, we expect stronger effects of the sexual sphere (e.g., frequency, sexual behaviour) among boys, and stronger effects of the relational sphere among girls.

H3 - Regarding the macro-level factors, we expect to find a double effect of religion on SS: a positive effect among students who have not transitioned to intercourse due to their adherence to their beliefs, and vice versa, a negative effect on those who experienced intercourse, caused by their feeling of guilt.

\section{Data, measures and methods}

\section{Data and measures}

The analyses were carried out on data collected in 2017 by the SELFY Survey, the second survey ${ }^{1}$ conducted in Italy to study the sexual and emotional attitudes and behaviour of Italian university students. The final sample included 7842 units; a poststratification at the macro-region level made it representative at the national level (Dalla Zuanna et al., 2019). The questionnaire was self-administered by the students and sexual satisfaction was assessed with one item ('As a whole, how would you define your current sex life?'), as is often the case in large national studies of sexual behaviour (Sánchez-Fuentes et al., 2014). The question was placed at the end of the SELFY questionnaire and had five response options, ranging from 'very dissatisfied' to 'very

\footnotetext{
${ }^{1}$ The SELFY survey, coordinated by a group of researchers from the Universities of Padua, Florence and Messina, was carried out in the first half of 2017 at 28 Italian public universities, in undergraduate courses in economics and statistics (for more details, see the Appendix in Dalla Zuanna et al., 2019). It is almost identical to another survey carried out in 2000 (Dalla-Zuanna \& Crisafulli, 2004); nevertheless, some questions, crucial for the approach adopted in this paper, were not present in the first questionnaire - for example, questions regarding masturbation, as well as the use of the Internet, impeding the comparison of sexual transition in 2000 with that in 2017.
} 
satisfied'. The structure of the modes allowed us to consider it as a scale (ranging from $-2=$ 'very dissatisfied' to $+2=$ 'very satisfied').

Following Sánchez-Fuentes et al. (2014), as independent variables, we introduced in the models variables representing the micro-, meso-, and macro-level dimensions. We excluded the exo-level variables from the analysis (factors related to social support, family relationships, socio-economic status, resources etc.) because, as was pointed out in the theoretical framework section, they generally have less impact on sexual satisfaction among youths (Higgins et al., 2011; Pedersen \& Blekesaune, 2003). In this specific case, with the sample being selected by age and professional condition (students from public universities), the effects of the exo factors are reduced even further. As for family relationships, results of preliminary analyses ${ }^{2}$ showed that dialogue with parents about sexual matters (which conveys the family relationships) was not significantly associated to sexual satisfaction.

\section{Micro-level variables}

First, we considered the most significant variables identified in the literature regarding self-esteem, and we created the variable Self-perception by combining the question about self-body image and the question about self-confidence. ${ }^{3}$ Due to evidence in the literature suggesting a strong association between these variables, especially among girls, we opted not to consider them separately (Agam et al., 2015; Auslander et al., 2007; Higgins et al., 2011; Milhausen et al., 2015). The variable Self-perception has the following categories: 'Feeling ugly and self-confident' (reference); 'Feeling beautiful and self-confident'; 'Feeling beautiful and quite self-confident'; 'Feeling beautiful and not self-confident'; and 'Feeling ugly and not self-confident'.

As stated previously, the masculine-feminine dichotomisation of the social construction of sexuality (Crawford \& Popp, 2003; Hofstede, 1998) is a further micro-level factor crucial to our aims. We chose to measure this factor by focusing on opinions regarding the sexual debut of boys and girls, as it is a milestone in the sexual development of an individual. We introduced two variables to describe this perspective. The first, Agreement with the earliness of first intercourse for her/his own gender ('Do you approve of very early intercourse of a boy/girl?') with categories 'No' (reference), 'Little', 'Quite' and 'Yes'. The second variable was based on the same questions but considered the accordance/discordance between the opinions related to two genders. This variable reflects the symmetry/asymmetry between the two answers: therefore, Gender symmetry of opinions was coded 'Yes' (reference) if the two answers coincide, 'No' otherwise.

To describe the sphere of sexual biography, we introduced the variable Sexual transitions. This is a synthetic indicator that refers to three sexual experiences: masturbation, petting and intercourse (Higgins et al., 2011; Levin, 2007; Miller et al., 2019). The

\footnotetext{
${ }^{2}$ Available upon request.

${ }^{3}$ The variable Self-perception is a combination of the question (D5 in the questionnaire) "Are you currently satisfied with your physical appearance?" (with the categories: 'No', 'A little', 'Quite', 'Yes') and the item (N53) "I feel insecure and inadequate, I cannot deal with life situations" (with the categories: 'Totally disagree', 'Quite disagree', 'Indifferent', 'Quite agree', 'Totally agree'). We defined the categories of the variable Selfperception as follows: 'Feeling ugly and self-confident' if D5 is at most 'A little' and N53 at most 'Indifferent'; 'Feeling beautiful and self-confident' if D5 is at least 'Quite' and N53 is 'Totally disagree'; 'Feeling beautiful and quite self-confident' if D5 is at least 'Quite' and N53 is 'Quite disagree'; 'Feeling beautiful and not selfconfident' if D5 is at least 'Quite' and N53 at least 'Indifferent'; finally, 'Feeling ugly and not self-confident' if D5 is at most 'A little' and N53 at least 'Quite agree'.
} 
transition to each sexual experience occurs if the respondent has experienced the event at least once. In our sample, no student declared the transition to intercourse without petting; therefore, the synthetic indicator was coded as follows: 'Complete sexual transition' (reference) if the three sexual experiences had occurred; 'Petting and intercourse transitions' if the respondent had experienced petting and intercourse; 'Masturbation and petting transitions' if the student had experienced both masturbation and petting; 'Petting transition' and 'Masturbation transition' if the interviewee had experienced, respectively, only petting or masturbation; 'No sexual transitions' if the student declared none of the three sexual experiences. To complete the sexual biography, we included the variables Age at first intercourse (Higgins et al., 2011; Pedersen \& Blekesaune, 2003), Number of sexual partners, and the dummy variable Sexual Orientation ('Hetero' reference) (Henderson et al., 2009).

Furthermore, we introduced a variable measuring the use of pornography on the Internet, Internet Pornography (Maddox et al., 2011; Štulhofer et al., 2010), as the combination of two questions regarding the exchange of sexy images/videos by smartphone and browsing pornographic websites. The indicator was coded as follows: 'Never' (reference), if the answer to both questions was 'Never'; 'Sometimes' if at least one of the two answers was 'Sometimes' and the other was 'At most, sometimes'; and 'Often' if the respondent reported 'Often' in at least one of the two answers.

Finally, we considered age and gender ('Girl' reference) as demographic variables.

\section{Meso-level variables}

This level refers to the relational dimension, we checked in each biography for the existence of a relational experience (Pedersen \& Blekesaune, 2003), the length of the current relationship (Heiman et al., 2011; Rehman et al., 2011) or the time elapsed since the last relationship. More specifically, the variable Relationship described the sentimental transition and assumed three categories: 'Never had a relationship'; 'In the past, but not currently'; and 'Currently in a relationship'. If the respondent reported 'Never', the sentimental transition did not occur; otherwise, the respondent had experienced the sentimental transition. The variable Duration in/out of a relationship was coded: 'Duration in: less than 1 year (reference); 'Duration in: 1 year'; 'Duration in: 23.5 years'; 'Duration in: 3.5 years and more'; 'Duration out: less than 1 year'; 'Duration out: 1 year'; 'Duration out: 2 years'; and 'Duration out: 3 or more years'.

Regarding sexual behaviour, we considered two variables. The first, Frequency of intercourse (Sánchez-Fuentes et al., 2014), was based on the following question: "In the last three months, how often have you had intercourse?" The variable was coded as follows: 'Never'; 'No more than once a month'; '2-3 times a month'; 'Once a week'; '2-3 times a week'; and 'More than 3 times a week' (reference). The second, Loveless intercourse, was based on the following question, "Have you had intercourse without feeling affection for the partner?" we recoded it with the categories 'No' (reference) and 'Yes'.

\section{Macro-level variables}

As for the macro determinants, like most of the literature (Higgins et al., 2010; Regnerus, 2007), we studied the religious aspect by introducing three variables. ${ }^{4}$ The

${ }^{4}$ We tested the existence of collinearity, and results showed no collinearity among these variables. 
first, Importance of religion in my life, measured the personal evaluation of religious belief with the following categories: 'Not at all' (reference); 'Quite important'; and 'Very important'. The second, Practising religion, related to the practice of religion (going to Mass and attending religious groups). It was obtained from the variables 'Attendance at Mass' and 'Participation in religious groups', and was a dichotomous variable with the reference category 'Not frequently'. Finally, the third variable, Parents practising religion during the student's pre-adolescence, measured parents' attendance at Mass during preadolescence of the students, with the categories 'Frequently', 'Sometimes' and 'Not at all' (reference).

The final sample, which excluded 403 respondents due to missing information, included 7439 students. ${ }^{5}$ Descriptive statistics of the variables and the indicators are shown in Table 1.

\section{Methods}

In order to test our hypothesis, although the original variable of self-evaluation of sexual satisfaction was an ordinal variable, we had to opt for logistic regression models. The natural choice of an ordinal model fell through after the Brant test revealed its inadequacy due to the non-respect of the proportional odds assumption (Scott Long \& Freese, 2014: 309). In addition, literature questioned the use of variable with a neutral position, like our SS variable, as ordinal (Scott Long \& Freese, 2014; Sturgis, Roberts, \& Smith, 2014). The next option of applying a multinomial model based on three categories ('dissatisfied', 'neither satisfied nor dissatisfied', 'satisfied') was set aside for two reasons: first, the estimates were particularly unstable, as preliminary analysis showed ${ }^{6}$; second, previous studies highlighted that the use of a mid-point/middle alternative/neutral position introduces ambiguity and that the use of 3-point scales (negative, neutral and positive) compared to 2-point scales (negative and positive) have significantly poorer reliability (O'Muircheartaigh, Krosnick, \& Helic, 2000). We therefore considered the logistic model, as despite entailing a loss of information, it ensures a more reliable result. To this end, we considered as a dependent variable the original variable Sexual satisfaction recoded in two categories: 'Satisfied' (combining the categories 'Very satisfied' and 'Quite satisfied') and 'Other' (combining 'Neither satisfied nor dissatisfied', 'Quite dissatisfied' and 'Very dissatisfied') used as a reference category. The decision to group 'Neither satisfied nor dissatisfied' with 'Dissatisfied' is justified by the fact that the individuals who declared a neutral position or being dissatisfied have a similar distribution according to the covariates introduced in the model, and therefore this decision allows us to have a higher sample size compared to a multinomial logistic regression while guaranteeing interpretable results. Moreover, it should be notice that previous studies (O'Muircheartaigh et al., 2000) found that omitting the middle alternative, the respondents chose negative position rather than the positive one.

Specifically, the first hypothesis ( $\mathrm{H} 1)$ was tested by comparing the overall sample (Model 1) with the complementary subgroups of students who did not complete the sexual transition to intercourse (Model 2) and, vice-versa, students who completed the

\footnotetext{
${ }^{5}$ We excluded respondents who did not answer the key questions (sexual satisfaction, sexual transition) for our purpose.

${ }^{6}$ Having 3 categories for the outcome variable considerably reduces the number of cases for each cell and this affects the stability of the estimates.
} 
Table 1 Distribution of descriptive statistics among university students, by gender* (SELFY, 2017, weighted data)

\begin{tabular}{llr}
\hline & Girls & Boys \\
\hline Sexual satisfaction & & 53.1 \\
Satisfied & 61.5 & 46.9 \\
Other & 38.5 & 100
\end{tabular}

Internet pornography (\%)

Never

65.2

6.5

Sometimes

Often

Loveless intercourse (\%)

No

Yes

Frequency intercourse in the last 3 months (\%)

Never

No more than once a month

2-3 times a month

Once a week

2-3 times a week

$>3$ times a week

Sexual Orientation (\%)

Hetero

Not hetero

Self-perception (\%)

Feeling beautiful and self-confident

Feeling beautiful and quite self-confident

Feeling beautiful and no self-confident

Feeling ugly and no self-confident

Feeling ugly and self-confident

Agreement with the earliness of first intercourse for her/his own gender (\%)

No

Little

Quite

Yes

Gender symmetry of opinions (\%)

Yes

No

Importance of religion in life (\%) 
Table 1 Distribution of descriptive statistics among university students, by gender* (SELFY, 2017, weighted data) (Continued)

\begin{tabular}{lll}
\hline & Girls & Boys \\
\hline Not at all & 19.0 & 32.0 \\
Quite important & 68.7 & 59.8 \\
Very important & 12.3 & 8.2 \\
& 100 & 100 \\
Practicing religion (\%) & & 93.9 \\
Not frequent & 89.6 & 6.1 \\
Frequent & 10.4 & 100 \\
& 100 & 20.1 \\
Parents practicing religion in student pre-adolescence (\%) & & 63.7 \\
No & 17.7 & 16.2 \\
Sometimes & 66.0 & 100 \\
Frequently & 16.3 & 2.0 \\
& 100 & 17.3 \\
Number of sexual partners (average) & 1.7 & 21.2 \\
Age at first intercourse (average) & 17.2 & 2.3 \\
Age (average) & 21.1 & \\
Duration of current relationship (average) & 2.6 & \\
\hline
\end{tabular}

Source: 2017 SELFY Databases

${ }^{*}$ Gender difference significant at $p<0.05$

sexual transition to intercourse (Model 3). The covariates were chosen with respect to the step of the sexual transition considered in the model. Specifically, the meso-dimension variables regarding the characteristics of the relationship (duration and frequency of intercourse) were present only in the models with students who completed the sexual transition (Model 3), while for Model 1, we made the most conservative choice, equal to Model 2 - that is, considering overall micro and macro dimensions. The second hypothesis $(\mathrm{H} 2)$ was tested by adding two logistic regression models, separately for gender, regarding the students who completed the sexual transition and were in a relationship when interviewed (Model 4 and Model 5). We opted for the comparison among students who had transitioned to complete sexual adulthood and with a partner, that is the case in which we can test all the considered dimensions (micro, meso and macro).

For the third hypothesis (H3), we compared the results of all the models.

\section{Results}

Among the Italian university students, the majority declared themselves to be sexually satisfied (Table 1), and boys do it more often than girls, with a statistically significant difference. Considering the two most influential factors for sexual satisfaction as pointed out by the literature, transition to intercourse and having a partner, the preliminary picture of Italian university students' sexual satisfaction is similar to the one that has emerged in other studies (Table 2). Most of the students made the transition to intercourse (80.4\%) as well as to a sentimental relationship (84.4\%). Girls were more involved in these transitions than were their male peers, who instead declared to have experienced the transition to masturbation more frequently than young women. Only 
Table 2 Average sexual satisfaction $\left(\mu_{S S}\right)$ and percentage distribution by gender ${ }^{a}$, sentimental and sexual transitions

\begin{tabular}{|c|c|c|c|c|c|c|c|c|c|c|c|c|c|}
\hline \multirow[t]{4}{*}{ Sexual transitions } & \multirow[t]{4}{*}{$\%$} & \multicolumn{12}{|c|}{ Relationship } \\
\hline & & \multicolumn{4}{|c|}{ Currently } & \multicolumn{4}{|c|}{ Never had } & \multicolumn{4}{|c|}{ In the past, not currently } \\
\hline & & \multicolumn{2}{|c|}{ Women } & \multicolumn{2}{|l|}{ Men } & \multicolumn{2}{|c|}{ Women } & \multicolumn{2}{|l|}{ Men } & \multicolumn{2}{|c|}{ Women } & \multicolumn{2}{|l|}{ Men } \\
\hline & & $\mu_{S S}$ & $\%$ & $\mu_{s s}$ & $\%$ & $\mu_{s s}$ & $\%$ & $\mu_{s s}$ & $\%$ & $\mu_{s s}$ & $\%$ & $\mu_{s s}$ & $\%$ \\
\hline Complete sex transition & 56.9 & 1.41 & 10.47 & 1.31 & 17.81 & 0.44 & 1,34 & 0.35 & 3,93 & -0.17 & 5.41 & 0.07 & 17.90 \\
\hline Masturbation + petting & 7.5 & 1.21 & 0.27 & 0,16 & 1.15 & -1.27 & 0,56 & -1.04 & 1,06 & -0.73 & 1.24 & -0.91 & 3.20 \\
\hline Masturbation & 4.6 & & & 0.06 & 0.07 & -0.86 & 0,57 & -0.82 & 3,00 & -0.84 & 0.27 & -0.88 & 0.70 \\
\hline Petting + Intercourse & 23.6 & 1.45 & 13.41 & 1.24 & 0,93 & 0.75 & 1,70 & 0.58 & 0,38 & -0.07 & 5.93 & 0.05 & 1.24 \\
\hline Petting & 4.4 & 0.80 & 0.94 & 1.16 & 0,03 & -0.08 & 0,83 & -1.25 & 0,15 & -0.61 & 2.26 & -0.32 & 0.19 \\
\hline No transitions & 3.1 & 0.10 & 0.12 & & & $-0,64$ & 1,66 & -0.21 & 0,40 & -0.56 & 0.83 & -0.27 & 0.04 \\
\hline Total & 100 & & 25.21 & & 19.99 & & 6.66 & & 8.92 & & 15.94 & & 23.27 \\
\hline
\end{tabular}

Source: 2017 SELFY Databases

${ }^{\mathrm{a}}$ Gender difference (significant at $p<0.05$ ) was tested only for groups greater than $5 \%$

$7.7 \%$ of the students had no sexual experience with a partner - that is, no experience or only masturbation. The percentage of those who had never had a romantic relationship was still higher (15.6\%). Students with a partner who had made the transition to intercourse were the most satisfied $\left(\mu_{\mathrm{SS}}>1\right)$, representing $42.6 \%$ of the sample, with $23.9 \%$ being girls and $18.7 \%$ boys. In contrast, the most dissatisfied $\left(\mu_{S S}<0\right), 28.3 \%$ of the sample, were characterized, above all, by the absence of a partner; girls were the majority of this subgroup (almost 20\%). Regarding gender differences, these preliminary results highlight that girls expressed stronger, statistically significant (positive or negative) evaluations than boys did.

To better interpret these results in light of our hypotheses, we performed logistic regression models on different groups of students based on their stages of sexual and sentimental transitions; this allows us to add to the models some specific variables for the selected group, such as the length of the relationship and the age at first intercourse (Table 3).

Results of Models 1-3 support our hypothesis H1. Students who have not experienced intercourse, regardless of the level of sexual experience, have lower sexual satisfaction compared to those who completed the sexual transition (Model 1). The transition to intercourse is the real divide for satisfaction, with the only exception being the comparison with young students with intercourse transition, but without masturbation transition, not being statistically significant. Nevertheless, among the students who have not yet transitioned to intercourse (Model 2), students without sexual transition are less satisfied compared to students who experienced petting and masturbation, and this is the only statistically significant comparison. Results of Models 1-3 highlight that beside the sexual transition, the sentimental transition has a crucial and positive impact on sexual satisfaction: not being in a relationship or never having had a relationship considerably reduces SS, and the shorter the time that has elapsed since the last relationship, the lower the satisfaction. The SS is lower immediately after the end of a relationship. The current relational condition is decisive - that is, the presence or absence of a partner significantly amplifies or depresses sexual satisfaction among students who have already transitioned to a romantic relationship, and being in a relationship has the most relevant effect in the absence of a complete sexual transition (Model 2). 
Table 3 Odds ratio of the logistic regression models with dependent variable sexual satisfaction (reference category 'Other')

\begin{tabular}{|c|c|c|c|c|c|}
\hline & Mod1 & Mod2 & Mod3 & Mod4 & Mod5 \\
\hline & $\begin{array}{l}\text { All } \\
\text { sample }\end{array}$ & $\begin{array}{l}\text { No intercourse } \\
\text { transition }\end{array}$ & $\begin{array}{l}\text { Intercourse } \\
\text { transition (IT) }\end{array}$ & $\begin{array}{l}\text { IT \& currently in } \\
\text { relationship, Boys }\end{array}$ & $\begin{array}{l}\text { IT \& currently in } \\
\text { relationship, Girls }\end{array}$ \\
\hline \multicolumn{6}{|c|}{ Self-perception (Feeling ugly and self-confident, ref.) } \\
\hline $\begin{array}{l}\text { Feeling ugly and not } \\
\text { self-confident }\end{array}$ & $0.568^{* * *}$ & 0.453 & $0.631^{*}$ & 0.471 & $0.271^{* *}$ \\
\hline $\begin{array}{l}\text { Feeling beautiful and } \\
\text { not self-confident }\end{array}$ & 0.846 & 1.547 & 0.833 & 0.916 & 0.745 \\
\hline $\begin{array}{l}\text { Feeling beautiful and } \\
\text { quite self-confident }\end{array}$ & $1.298^{*}$ & 1.357 & $1.440^{*}$ & 1.197 & 1.905 \\
\hline $\begin{array}{l}\text { Feeling beautiful and } \\
\text { self-confident }\end{array}$ & $2.325^{* * *}$ & $3.035^{* *}$ & $2.303^{* * *}$ & $2.471^{*}$ & 1.863 \\
\hline Gender (girl, ref.) & 1.045 & 1.785 & 1.182 & & \\
\hline \multicolumn{6}{|c|}{ Agreement with the earliness of first intercourse for her/his own gender (No, ref.) } \\
\hline Little & 0.843 & 0.708 & 0.819 & 0.833 & $0.479^{* *}$ \\
\hline Quite & 1.097 & 1.407 & 0.898 & 0.984 & 1.056 \\
\hline Yes & 1.224 & 1.636 & 0.923 & 0.616 & $0.051^{* * *}$ \\
\hline $\begin{array}{l}\text { Gender symmetry of } \\
\text { opinions (Yes, ref.) }\end{array}$ & $0.804^{* *}$ & 0.611 & $0.770^{*}$ & 0.670 & $0.398^{* *}$ \\
\hline \multicolumn{6}{|c|}{ Sexual transitions (Complete sexual transition, ref.) } \\
\hline No sexual transitions & $0.045^{* * *}$ & $0.316^{* *}$ & & & \\
\hline Masturbation & $0.064^{* * *}$ & 0.819 & & & \\
\hline Petting & $0.136^{* * *}$ & 1.481 & & & \\
\hline $\begin{array}{l}\text { Masturbation and } \\
\text { Petting }\end{array}$ & $0.078^{* * *}$ & Ref. & & & \\
\hline Petting and Intercourse & 0.886 & & 1.091 & 5.202 & 0.739 \\
\hline Age at first intercourse & & & 1.012 & 1.025 & 1.143 \\
\hline Number of sexual partners & & & $1.183^{* *}$ & 1.231 & 1.233 \\
\hline $\begin{array}{l}\text { Sexual Orientation (Hetero, } \\
\text { ref.) }\end{array}$ & 0.821 & $3.265^{* * *}$ & $0.603^{* *}$ & 0.522 & 0.745 \\
\hline \multicolumn{6}{|c|}{ Internet pornography (Never, ref.) } \\
\hline Sometimes & $0.698^{* *}$ & $0.212^{* * *}$ & 0.842 & 0.227 & 0.995 \\
\hline Often & $0.552^{* * *}$ & $0.137^{* * *}$ & $0.663^{*}$ & 0.212 & 0.937 \\
\hline Age & $1.055^{*}$ & $1.254^{*}$ & $0.917^{*}$ & 0.887 & $0.787^{*}$ \\
\hline
\end{tabular}

Relationship (Currently in a relationship, ref.)

$\begin{array}{lll}\text { In the past, not } & 0.049^{* * *} & 0.054^{* * *} \\ \text { currently } & & \\ \begin{array}{l}\text { Never had a } \\ \text { relationship }\end{array} & 0.100^{* * *} & 0.078^{* * *}\end{array}$

Duration in/out of the relationship (Duration in: less than 1 year, ref.)

$\begin{array}{llll}\text { Duration in: } 1-2 \text { years } & 1.322 & 1.160 & 1.328 \\ \text { Duration in: } 2-3,5 \text { years } & 1.551 & 1.690 & 1.437 \\ \text { Duration in: } 3,5 \text { or more } & 1.686^{* * *} & 1.930 & 2.063 \\ \begin{array}{l}\text { Duration out: less than } \\ 1 \text { year }\end{array} & 0.192^{* * *} & & \\ \text { Duration out: } 1-2 \text { years } & 0.197^{* * *} & & \\ \text { Duration out: } 2-3.5 \text { years } & 0.244^{* * *} & & \\ \text { Duration out: } 3.5 \text { years } & 0.265^{* * *} & & \\ \text { or more } & & \end{array}$


Table 3 Odds ratio of the logistic regression models with dependent variable sexual satisfaction (reference category 'Other') (Continued)

\begin{tabular}{|c|c|c|c|c|c|}
\hline & Mod1 & Mod2 & Mod3 & Mod4 & Mod5 \\
\hline & $\begin{array}{l}\text { All } \\
\text { sample }\end{array}$ & $\begin{array}{l}\text { No intercourse } \\
\text { transition }\end{array}$ & $\begin{array}{l}\text { Intercourse } \\
\text { transition (IT) }\end{array}$ & $\begin{array}{l}\text { IT \& currently in } \\
\text { relationship, Boys }\end{array}$ & $\begin{array}{l}\text { IT \& currently in } \\
\text { relationship, Girls }\end{array}$ \\
\hline \multicolumn{2}{|l|}{$\begin{array}{l}\text { Never had a } \\
\text { relationship }\end{array}$} & & \multicolumn{2}{|l|}{$0.391^{*}$} & \\
\hline \multicolumn{6}{|c|}{ Frequency intercourse in the last 3 months (> 3 times a week, ref.) } \\
\hline \multicolumn{3}{|l|}{ Never } & $0.010^{* * *}$ & $0.005^{* * *}$ & $0.006^{* * *}$ \\
\hline \multicolumn{3}{|l|}{$\begin{array}{l}\text { No more than once a } \\
\text { month }\end{array}$} & $0.034^{* * *}$ & $0.015^{* * *}$ & $0.016^{* * *}$ \\
\hline \multicolumn{3}{|l|}{ 2-3 times a month } & $0.123^{* * *}$ & $0.036^{* *}$ & $0.039^{* *}$ \\
\hline \multicolumn{3}{|l|}{ Once a week } & $0.258^{* *}$ & $0.112^{*}$ & 0.161 \\
\hline \multicolumn{3}{|l|}{ 2-3 times a week } & 0.519 & $0.149^{*}$ & 0.588 \\
\hline \multicolumn{6}{|c|}{ Loveless intercourse (No, ref.) } \\
\hline \multicolumn{2}{|l|}{ Yes } & & $0.710^{* *}$ & 0.539 & 0.592 \\
\hline \multicolumn{6}{|c|}{ Importance of religion in life (Not at all, ref.) } \\
\hline Quite important & 1.066 & 1.469 & 0.781 & $0.476^{*}$ & 1.152 \\
\hline Very important & 1.261 & $5.066^{* * *}$ & $0.938^{*}$ & 0.966 & 1.634 \\
\hline $\begin{array}{l}\text { Practicing religion (Not } \\
\text { frequent, ref.) }\end{array}$ & 1.221 & 1.551 & 1.158 & 3.348 & 1.000 \\
\hline \multicolumn{6}{|c|}{ Parents practicing religion in student's pre-adolescence (No, ref.) } \\
\hline Sometimes & $0.798^{*}$ & $0.557^{*}$ & 0.926 & 1.652 & 0.419 \\
\hline Frequently & 0.978 & 0.610 & 1.091 & $3.062^{*}$ & $0.305^{*}$ \\
\hline Constant & yes & yes & yes & yes & yes \\
\hline N & 7439 & 1454 & 5985 & 1366 & 1721 \\
\hline
\end{tabular}

As far as the other variables, grouped in the micro level, are concerned, Models 1-3 highlight that self-esteem significantly impacts SS. Compared to 'Feeling ugly and selfconfident', on the one hand, 'Feeling beautiful and (at least quite) self-confident' increases SS among both students who have transitioned to intercourse and those who have not, while on the other hand, the perception of being not self-confident significantly decreases SS among those who have transitioned to intercourse, as compared to an impact that is not significant among students without this transition.

Considering opinions on the sexual debut of boys and girls (measured by the two variables "Agreement with the earliness of first intercourse for her/his own gender" and "Gender symmetry of opinions"), only an asymmetric attitude has a significant effect with negative association with SS, particularly among students transited to intercourse (Model 3). Sexual orientation affects students differently depending on the sexual stage reached. Among the students who have not completed the sexual transition (Model 2), sexual orientation significantly increases SS, while it has a negative effect among those who have completed the sexual transition (Model 3).

As far as sexual attitudes are concerned, Internet pornography is shown to be negatively interrelated with SS, especially among students who are still in transition towards sexual adulthood; however, the only statistically significant results among students who have transitioned to intercourse is in the case of frequent use ('often'). 
Finally, student age has varying impacts depending on whether the transition to intercourse has occurred. The older the students, the greater the satisfaction among those who have not completed the transition; otherwise, the effect is negative.

Regarding the meso-level dimension (Model 3), the Frequency of intercourse has a relevant impact on SS, regardless of being in a relationship or not. Having intercourse once a week or less is associated to a considerably lower SS compared to those who have the highest frequency (more than 3 times a week), while there are no significant differences between the categories '2-3 times a week' and 'more than 3 times'. In addition, the Number of sexual partners has a positive and significant association with SS.

Regarding H2, the first results in Models 1-3 did not show significant gender effect in the level of SS. Nevertheless, focusing on the subgroup of students who have completed the sexual and sentimental transitions, and are currently with a partner, we fitted Models 4 and 5, whose results highlight that some factors influence young men and young women differently, supporting our hypothesis.

As for the micro-dimension variables, the influence of self-esteem differs slightly between boys and girls. Compared to feeling ugly and self-confident, among both boys and girls, feeling beautiful (and self-confident) considerably increases the likelihood of SS among boys, while SS decreases with statistical significance only for girls who do not feel self-confident (and ugly). Opinion on sexual debut affects significantly only girls with a negative effect on SS; in particular, an asymmetric gender opinion on very early sexual debut has a significant negative impact, decreasing the likelihood of SS.

Regarding the meso level, we observe that the most influential factor is frequency of intercourse. For a frequency lower than once a week among both boys and girls, the probability of satisfaction is lower, while among students with a higher frequency of intercourse, this variable has a different effect depending on gender. As expected, this aspect is more relevant for boys, since for them any frequency compared to more than 3 times a week is depressing and statistically significant, while it is not significant for girls above once a week. Comparing boys and girls, the other meso-level variables do not significantly affect SS, and the direction of the effect is usually identical.

As for the macro level (religious dimension), the results of the models show the varying influence of religion according to the stage of sexual and sentimental transition, partly supporting our hypothesis H3. The role of religion, as a personal belief, is significantly positive when increasing SS among students who are still in transition towards sexual adulthood, but it reverses its influence among students who have completed sexual transition. This effect is less impacting among students, who have a partner. Finally, the religious practice of respondents' parents during their pre-adolescence has a slightly different effect on SS by gender. Compared to having parents who do not practise religion at all, only male students with parents who frequently practise religion are more satisfied, and conversely, only female students having parents who practise frequently are less satisfied.

\section{Conclusions}

This paper examines the determinants of sexual satisfaction among Italian young men and women at the beginning of adulthood, taking into consideration the stage of sentimental and sexual transition that had been reached. The picture that emerges confirms the overall results of previous studies conducted in other Western countries. Above all, sexual satisfaction is positively associated with the frequency of intercourse within a 
stable and exclusive relationship, confirming previous literature (Dalla Zuanna et al., 2019; Pedersen \& Blekesaune, 2003; Sánchez-Fuentes et al., 2014). However, our results highlight that the combination of sexual and sentimental transitions can affect SS both positively and negatively, supporting our hypothesis H1. The results of the models clearly show the positive effect on SS of the transition to intercourse, and conversely, they show a greater dissatisfaction when transition occurs without having a partner. The other sexual transitions (masturbation and petting) do not have a strong effect, except for students who did not yet transition to intercourse, for whom the fact of not having any sexual experience decreases SS. The sentimental transition has a crucial effect in increasing satisfaction when the partner is present, while increasing dissatisfaction when they are not. Sentimental and sexual transitions are ultimately 'joys and sorrows', meaning that they lead to more intense levels, both in a positive and negative sense, of sexual satisfaction depending on the stage of sexual and sentimental transitions and on the presence or absence of a partner.

As for the H2 hypothesis, our results only partially support it. The variable "gender" is not statistically significant in the first three models: there is no difference between girls and boys in terms of sexual satisfaction among students both with complete sexual transition and those without it, all other characteristics being equal. In the same way, concerning biography, sexual attitude and behaviour do not differ significantly between the two genders, with the exception of sexual intercourse frequency. This last factor is the only one, with the character of 'performance', that is statistically significant in influencing boys' SS more than that of girls. This interest in performance is present among young men, but the same cannot be said for the female representation of sexual satisfaction, and moreover as for the relational aspect (duration of relationship) there is no difference between the two genders. Our results, therefore, confirm the studies that emphasize a convergence of the two genders in the level of SS (Higgins et al., 2011; Petersen \& Hyde, 2010), but it should be noted that our results are affected by the limitation of the availability of meso variables regarding the relationship characteristics of couples (for example, relationship satisfaction, partner support, equity, communication). Girls differ from boys more at the micro level rather than on the relationship side. Feeling beautiful has a positive effect on both genders but it is significant only among boys, while lacking self-confidence seems to have a negative and significant effect on girls only; these results are in line with the literature regarding the effect of self-esteem (Bajos et al., 2010; Calogero \& Thompson, 2009; Pujols et al., 2010). Furthermore, asymmetric gender opinions on sexual debut have a negative effect on SS for both genders, but significant only for girls.

As for the role of the macro dimension expressed by the importance and practice of religion, our results partly support hypothesis H3. Strong personal belief (religion is "important" in life) shows a protective effect for students having not yet transitioned to intercourse, while a negative effect when transition happened. However, considering boys and girls distinctly, with the sexual debut behind them and currently with a partner, the effect of religion is significant only among boys who declare it as 'quite important'. Therefore, religion has a positive effect if it corroborates a non-transition choice; but it seems to convey the hypothesised guilt effect only partially (Higgins et al., 2010; Regnerus, 2007). In fact, the religious practice of parents during pre-adolescence has a significant effect but different by gender, with a sense of guilt plausible only among girls. 
As a concluding remark, we should highlight that the results of this paper are affected by the measure used for sexual satisfaction, as it was derived from a single generic question in the absence of multiple questions investigating every single aspect of sexual life. This limitation leads to a generalization of SS that is less focalised on sexuality and more inclusive of sentimental aspects.

\section{Acknowledgements}

Not applicable.

\section{Authors' contributions}

LT designed the study, analysed and interpreted the data, and wrote the manuscript. SMLR analysed and interpreted the data, and revised the paper. EBB analysed and interpreted the data, and revised the paper. All authors read and approved the final manuscript The issue of the paper is in line with the aims and scopes of Genus, which relates also to the interrelations between demography and social phenomena. Finally, we declare that the content of the manuscript has not been published, or submitted for publication elsewhere. This paper goes to the following special issue: "Changes in the sexual behavior of young people".

Funding

Not applicable.

\section{Availability of data and materials}

The datasets generated and/or analysed during the current study are not publicly available.

\section{Competing interests}

The authors declare that they have no competing interests.

Received: 10 December 2019 Accepted: 6 August 2020

Published online: 15 September 2020

\section{References}

Agam, R., Tamir, S., \& Golan, M. (2015). Gender differences in respect to self-esteem and body image as well as response to adolescent's school-based prevention programs. Journal of Psychology \& Clinical Psychiatry, 2(5), 00092. https://doi.org/10. 15406/jpcpy.2015.02.00092

Auslander, B. A., Rosenthal, S. L., Fortenberry, J. D., Biro, F. M., Bernstein, D. I., \& Zimet, G. D. (2007). Predictors of sexual satisfaction in an adolescent and college population. Journal of Pediatric and Adolescent Gynecology, 20(1), 25-28.

Bajos, N., Wellings, K., Laborde, C., \& Moreau, C. (2010). Sexuality and obesity, a gender perspective: Results from French national random probability survey of sexual behaviours. British Medical Journal, 340, c2573.

Calogero, R. M., \& Thompson, J. K. (2009). Potential implications of the objectification of women's bodies for women's sexual satisfaction. Body Image, 6(2), 145-148.

Carpenter, L. (2005). Virginity lost: an intimate portrait of first sexual experiences. New York: New York University Press.

Carpenter, L. M., Nathanson, C. A., \& Kim, Y. J. (2009). Physical women, emotional men: gender and sexual satisfaction in midlife. Archives of Sexual Behavior, 38, 87. https://doi.org/10.1007/s10508-007-9215-y.

Carroll, J. S., Padilla-Walker, L. M., Nelson, L. J., Olson, C. D., McNamara Barry, C., \& Madsen, S. D. (2008). Generation XXX: pornography acceptance and use among emerging adults. Journal of Adolescent Research, 23(1), 6-30. https://doi.org/10. $1177 / 0743558407306348$.

Clay, D., Vignoles, V. L., \& Dittmar, H. (2005). Body image and self-esteem among adolescent girls: testing the influence of sociocultural factors. Journal of Research on Adolescence, 15, 451-477. https://doi.org/10.1111/j.1532-7795.2005.00107.x.

Crawford, M., \& Popp, D. (2003). Sexual double standards: a review and methodological critique of two decades of research. The Journal of Sex Research, 40(1), 13-26. https://doi.org/10.1080/00224490309552163.

Dalla Zuanna, G., Caltabiano, M., Minello, A., \& Vignoli, D. (2019). Catching up! The sexual opinions and behaviour of Italian students (2000-2017), No 2019_02, Econometrics Working Papers Archive, Universita' degli Studi di Firenze, Dipartimento di Statistica, Informatica, Applicazioni "G. Parenti", https://EconPapers.repec.org/RePEc:fir:econom:wp2019_02. Accessed 10 Sept 2019.

Dalla-Zuanna, G., \& Crisafulli, C. (Eds.) (2004). Sexual behaviour of Italian students. Messina: University of Messina.

Davidson, J. K., Darling, C. A., \& Norton, L. (1995). Religiosity and the sexuality of women: Sexual behavior and sexual satisfaction revisited. Journal of Sex Research, 32, 235-243.

Furnham, A., Badmin, N., \& Sneade, I. (2002). Body image dissatisfaction: gender differences in eating attitudes, self-esteem, and reasons for exercise. The Journal of Psychology, 136(6), 581-596.

Haavio-Mannila, E., \& Kontula, O. (1997). Correlates of increased sexual satisfaction. Archives of Sexual Behavior, 26, 399-419.

Heiman, J. R., Long, J. S., Smith, S. N., Fisher, W. A., Sand, M. S., \& Rosen, R. C. (2011). Sexual satisfaction and relationship happiness in midlife and older couples in five countries. Archives of Sexual Behavior, 40, 741-753.

Henderson, A. W., Lehavot, K., \& Simoni, J. M. (2009). Ecological models of sexual satisfaction among lesbian/bisexual and heterosexual women. Archives of Sexual Behavior, 38, 50-65.

Higgins, J. A., Mullinax, M., Trussell, J., Davidson, J. K., \& Moore, N. B. (2011). Sexual satisfaction and sexual health among university students in the United States. American Journal of Public Health, 101, 1643-1654.

Higgins, J. A., Trussell, J., Moore, N. B., \& Davidson, J. K. (2010). Virginity lost, satisfaction gained? Physiological and psychological sexual satisfaction at heterosexual debut. Journal of Sex Research, 47, 384-394. 
Ho, M. Y., Cheung, F. M., \& Cheung, S. F. (2008). Personality and life events as predictors of adolescents' life satisfaction: do life events mediate the link between personality and life satisfaction? Social Indicators Research, 89(3), 457-471. https://doi. org/10.1007/s11205-008-9243-6.

Hofstede, G. (1998). Attitudes, values and organizational culture: disentangling the concepts. Organization Studies, 19(3), 477493. https://doi.org/10.1177/017084069801900305.

Hurlbert, D. F., Apt, C., \& Rabehl, S. M. (1993). Key variables to understanding female sexual satisfaction: an examination of women in nondistressed marriages. Journal of Sex and Marital Therapy, 19, 154-165.

Ji, J., \& Norling, A. M. (2004). Sexual satisfaction of married urban Chinese. Journal of Developing Societies, 20, 21-38.

Lau, J. T. F., Kim, J. H., \& Tsui, H. Y. (2005). Mental health and lifestyle correlates of sexual problems and sexual satisfaction in heterosexual Hong Kong Chinese population. Urology, 66, 1271-1281.

Lawrance, K., \& Byers, E. S. (1995). Sexual satisfaction in long-term heterosexual relationships: the interpersonal exchange model of sexual satisfaction. Personal Relationships, 2, 267-285. https://doi.org/10.1111/j.1475-6811.1995.tb00092.x.

Levin, R. J. (2007). Sexual activity, health and well-being - the beneficial roles of coitus and masturbation. Sexual and Relationship Therapy, 22(1), 135-148. https://doi.org/10.1080/14681990601149197.

Levine, S. B. (1992). Sexual life: a clinician's guide. New York: Plenum Press.

Lindau, S. T., \& Gavrilova, N. (2010). Sex, health, and years of sexually active life gained due to good health: evidence from two US population based cross sectional surveys of ageing. British Medical Journal, 340, c810.

Maddox, A. M., Rhoades, G. K., \& Markman, H. J. (2011). Viewing sexually-explicit materials alone or together: associations with relationship quality. Archives of Sexual Behavior, 40, 441-448. https://doi.org/10.1007/s10508-009-9585-4.

McClelland, S. I. (2011). Who is the "self" in self reports of sexual satisfaction? Research and policy implications. Sexuality Research \& Social Policy, 8, 304-320.

Mercer, C. H., Tanton, C., Prah, P., Erens, B., Sonnenberg, P., Clifton, S., ... Johnson, A. M. (2013). Changes in sexual attitudes and lifestyles in Britain through the life course and over time: findings from the National Surveys of sexual attitudes and lifestyles (Natsal). The Lancet, 382, 1781-1794.

Milhausen, R. R., Buchholz, A. C., Opperman, E. A., \& Benson, L. E. (2015). Relationships between body image, body composition, sexual functioning, and sexual satisfaction among heterosexual young adults. Archives of Sexual Behavior, 44(6), 1621-1633.

Milhausen, R. R., \& Herold, E. S. (1999). Does the sexual double standard still exist? Perceptions of university women. The Journal of Sex Research, 36, 361-368.

Miller, D. J., McBain, K. A., Li, W. W., \& Raggatt, P. T. (2019). Pornography, preference for porn-like sex, masturbation, and men's sexual and relationship satisfaction. Personal Relationships, 26(1), 93-113.

Moyano, N., \& Sierra, J. C. (2013). Relationships between personality traits and positive/negative sexual cognitions. International Journal of Clinical and Health Psychology, 13, 189-196.

O'Muircheartaigh, C., Krosnick, J.A., \& Helic, A. (2000). Middle alternatives, acquiescence, and the quality of questionnaire data. Working Papers 0103, Harris School of Public Policy Studies, University of Chicago.

Oliver, M. B., \& Hyde, J. S. (1993). Gender differences in sexuality: a meta-analysis. Psychological Bulletin, 114, $29-51$.

Pedersen, W., \& Blekesaune, M. (2003). Sexual satisfaction in young adulthood: cohabitation, committed dating or unattached life? Acta Sociologica, 46(3), 179-193.

Petersen, J. L., \& Hyde, J. S. (2010). A meta-analytic review of research on gender differences in sexuality: 1993 to 2007. Psychological Bulletin, 13, 21-38.

Pujols, Y., Meston, C. M., \& Seal, B. N. (2010). The association between sexual satisfaction and body image in women. The Journal of Sexual Medicine, 7, 905-916.

Rainer, H., \& Smith, I. (2012). Education, communication and well-being: an application to sexual satisfaction. Kyklos, 65, 581-598. Regnerus, M. D. (2007). Forbidden fruit: sex and religion in the lives of American teenagers. New York: Oxford University Press.

Rehman, U. S., Rellini, A. H., \& Fallis, E. (2011). The importance of sexual self-disclosure to sexual satisfaction and functioning in committed relationships. The Journal of Sexual Medicine, 8, 3108-3115.

Sánchez-Fuentes, M., Santos-Iglesias, P., \& Sierra, J. C. (2014). A systematic review of sexual satisfaction. International Journal of Clinical and Health Psycology, 14(1), 67-75.

Schmiedeberg, C., \& Schröder, J. (2016). Does sexual satisfaction change with relationship duration? Archives of Sexual Behavior, 45(1), 99-107.

Scott Long, J., \& Freese, J. (2014). Regression models for categorical dependent variables using stata, (3rd ed., ). Texas: Stata Press Publication.

Sprecher, S. (2002). Sexual satisfaction in premarital relationships: associations with satisfaction, love, commitment, and stability. Journal of Sex Research, 39(3), 190-196.

Štulhofer, A., Buško, V., \& Brouillard, P. (2010). Development and bicultural validation of the new sexual satisfaction scale. Journal of Sex Research, 47, 257-268.

Sturgis, P., Roberts, C., \& Smith, P. (2014). Middle alternatives revisited: How the neither/nor response acts as a way of saying "I don't know"? Sociological Methods \& Research, 43(1), 15-38.

WHO (2006). Defining sexual health, Report of a technical consultation on sexual health, 28-31 January 2002. Geneva: WHO.

WHO (2010). Measuring sexual health: conceptual and practical considerations and related indicators, https://www.who.int/ reproductivehealth/publications/monitoring/who_rhr_10.12/en/ Accessed June 2019.

Young, M., Denny, G., Luquis, R., \& Young, T. (1998). Correlates of sexual satisfaction in marriage. Canadian Journal of Human Sexuality, 7, 115-128.

Young, M., Denny, G., Young, T., \& Luquis, R. (2000). Sexual satisfaction among married women. American Journal of Health Studies, 16, 73-84.

Ziherl, S., \& Masten, R. (2010). Differences in predictors of sexual satisfaction and in sexual satisfaction between female and male university students in Slovenia. Psychiatria Danubina, 22(3), 425-429.

\section{Publisher's Note}

Springer Nature remains neutral with regard to jurisdictional claims in published maps and institutional affiliations. 